\title{
КОНЦЕПТУАЛЬНЫЕ ПОДХОДЫ К ФОРМИРОВАНИЮ ОРГАНИЗАЦИОННО- ЭКОНОМИЧЕСКОГО МЕХАНИЗМА ДОСТИЖЕНИЯ ЦЕЛЕЙ УСТОЙЧИВОГО РАЗВИТИЯ В НАЦИОНАЛЬНОЙ АГРОПРОДОВОЛЬСТВЕННОЙ СИСТЕМЕ
}

\author{
(C) 2021 Довготько Наталья Анатольевна \\ кандидат экономических наук, доцент \\ Ставропольский государственный аграрный университет, Россия, Ставрополь \\ ведущий научный сотрудник \\ Пятигорский государственный университет, Россия, Пятигорск \\ E-mail:ndovgotko@yandex.ru \\ (c) 2021 Чередниченко Ольга Александровна \\ кандидат экономических наук, доцент \\ Ставропольский государственный аграрный университет, Россия, Ставрополь \\ E-mail: chered72@mail.ru
}

Выявлены основные предпосылки, факторы, тенденции и приоритетные направления формирования организационно-экономического механизма достижения целей устойчивого развития (ЦУР) в российской агропродовольственной системе в соответствии с целями и задачами Глобальной повестки дня на период до 2030 года (Повестка 2030), принципами продовольственной безопасности ФАО и условиями развития национальной экономики. Разработана концептуальная версия подобного механизма, определены его основные уровни, структурные подсистемы, методы достижения ЦУР с учетом необходимости их встраивания в систему стратегического планирования и государственные программы развития агропродовольственного сектора экономики. Предложено выделять экономические, организационные, социальные и природно-климатические подсистемы и соответствующие им инструменты для достижения ЦУР и согласования политики устойчивого развития в российской агропродовольственной системе.

Ключевые слова: организационно-экономический механизм, Повестка 2030, устойчивое развитие, цели устойчивого развития, агропродовольственная система, сельское хозяйство, продовольственная безопасность.

Введение. На современном этапе проблематика устойчивости является уникальной компетенцией для мирового сообщества, направленной на «достижение оптимального использования ограниченных ресурсов, использование экологичных технологий, сохранение целостности биологических и физических природных систем, стабильности социальных и культурных систем» [19]. Объединив национальные приоритеты с Повесткой 2030 [16], почти за шесть лет, прошедших с даты обсуждения и принятия данного документа, многие правительства, международные, региональные общественные организации предприняли новаторские шаги по реализации амбициозных глобальных целей устойчивого развития. Кроме того, отражением выхода на траекторию устойчивого развития человеческой цивилизации и глобальной экономики являются многочисленные международные инициативы по проблемам устойчиво- го роста, обсуждение релевантных проблем на международных симпозиумах и конференциях, а также увеличение количества публикаций по данной проблематике.

Однако красной нитью через всю Повестку 2030 проходит концепция продовольственной безопасности, которая прямо прописана в ЦУР 2 - Ликвидация голода, и косвенно находит отражение во всех остальных ее положениях. Бремя неполноценного питания во всех его формах остается вызовом глобального масштаба, так как «в 2019 году с острым отсутствием продовольственной безопасности столкнулись около 750 млн. человек, или практически каждый десятый житель планеты, 6,9\% (47,0 млн.) детей страдали от истощения, и, напротив, 5,6\% (38,3 млн.) - от избыточного веса» [20]. Согласно оценкам ООН, в 2030 году в мире будет насчитываться 8,6 млрд. человек, в 2050 году - 9,8 млрд. а в 2100 году уже 11,2 млрд. [14]. 
Кроме того, агропродовольственные системы (далее - АПС) играют ключевую роль в достижении ЦУР 3 - Хорошее здоровье и благополучие, ЦУР 12 - Ответственное производство и потребление, ЦУР 13 - Противодействие изменению климата и ЦУР 15 - Защита и восстановление экосистем суши. В этой связи эксперты ФАО отмечают, что «агропродовольственные системы включают важные сектораэкономики стран Европы и Центральной Азии и обеспечивают занятость и средства к существованию значительной части населения. Они обладают серьезным потенциалом для содействия достижению многих ЦУР, реализации Парижского соглашения» [17]. В свою очередь, отечественные исследователи утверждают, что «в перспективе 10-20 лет развитие глобального АПК будет диктоваться ростом угроз дефицита ресурсов для обеспечения растущих потребностей на фоне кризиса сложившихся моделей продовольственных систем и усиления необходимости обеспечения биобезопасности» [5].

Таким образом, продовольствие и сельское хозяйство находятся в центре внимания Повестки 2030, начиная с вопросов нивелирования проблем голода и неполноценного питания до борьбы с изменениями климата.

Литературный обзор. По данным Elsevier, за последние пять лет уже опубликовано более 4 млн. статей, связанных с ЦУР, общий объем исследований по этому направлению продолжает расти [26]. Так, многие зарубежные авторы утверждают о необходимости разработки последовательности действий по реализации ЦУР, а также инструментов для мониторинга и оценки прогресса в достижении целевых индикаторов и их интерпретации для принятия обоснованных управленческих решений в области достижения устойчивости [23]. Различные подходы к формированию механизмов реализации ЦУР активно разрабатываются с позиций таких новых областей, как цифровая трансформация, инновации и устойчивое потребление[24]. Кроме того, необходимые меры, принятые для реагирования на непосредственную угрозу COVID-19 как препятствие для стремления мира достичь ЦУР, в частности для бедных стран и групп населения, рассмотрены в Докладе об устойчивом развитии (2020), выполненном авторитетными специалистами Кембриджского университета [25].

В силу того, что проблематика достижения ЦУР ООН актуальна и для решения за- дач устойчивого развития современной России, отечественные ученые активно исследуют проблему продвижения ЦуР ООН в социо-эколого-экономических системах. Так, в работе С.Н.Бобылева и Л.М.Григорьева рассматриваются ЦУР как возможность для лучшей координации на пути выхода из рецессии после COVID-19 [2]. Наиболее актуальные проблемы реализации ЦУР на основе комплексного подхода проанализированы в работе А. Г. Сахарова и О.И.Колмар [10]. В свою очередь, в целевом исследовании Чередниченко О.А., Довготько Н.А. и Яшаловой Н.Н. раскрыты российские приоритеты и направления адаптации Повестки 2030 в агропродовольственном секторе Российской Федерации [12]. Е.В.Викторова и Д.А.Петренко приводят примеры прогрессивных законов в европейских странах и США и анализируют в этой связи принципы ответственного производства и потребления через призму ЦУР 12 [3]. Кроме того, российскими учеными изучается опыт Европейского союза по достижению ЦУР ООН в агропродовольственных системах и выявляются возможности его использования в России [4].

Однако следует признать, что в исследованиях российских ученых вопросам устойчивого развития и реализации ЦУР в национальной агропродовольственной системе уделяется все же недостаточное внимание.

Учитывая вышеизложенное, считаем, что назрела необходимость в формировании организационно-экономического механизма достижения ЦУР в национальной агропродовольственной системе с учетом корректной адаптации целей устойчивого развития $\mathrm{OOH}$ в российских условиях, что и является целью данной статьи.

Материалы и методы. Для обоснования перспектив формирования организационноэкономического механизма достижения ЦУР в российской агропродовольственной системе и дальнейшей его реализации авторами был использован разнообразный методологический инструментарий: системный подход и анализ, статистический и ситуационный анализ, экспертные оценки.

Результаты. Определяя концептуальные подходы к разработке и последующей реализации организационно-экономического механизма достижения ЦУР в национальной агропродовольственной системе, прежде всего отметим, что нами был проведен анализ действующих 
документов стратегического планирования, имеющих прямое или косвенное отношение к процессам производства продовольствия, его распределения, потребления и утилизации пищевых отходов, на соответствие их приоритетов целям и задачам устойчивого развития Повестки 2030. Здесь следует отметить, что авторский подход заключается в рассмотрении указанных процессов в рамках определенной социоэколого-экономической системы (в нашем случае - национальной агропродовольственной системы), включающей совокупность субъектов, участвующих в различных видах экономической деятельности по производству, переработке, распределению, потреблению и утилизации пищевых продуктов, производимых в сельском хозяйстве и перерабатывающих отраслях, а также элементы и факторы экономической, социальной и природной среды, в которой они функционируют. Также следует заметить, что, в отличие от понятий агропромышленного или продовольственного комплекса, категория «агропродовольственная система» в качестве одной из ключевых составляющих включает потребителей продуктов питания, формирующих спрос на продовольствие и модели потребления продуктов питания.

Между тем, актуализируя необходимость формирования подобного механизма, обратим внимание на мировые тренды и экспертные выводы ФАО о ключевых действующих и формирующихся взаимосвязанных факторах, влияющих на агропродовольственные системы, и соответствующих им тенденциях (см. таблицу 1).

Итак, в процессе формирования организационно-экономического механизма достижения ЦУР в АПС необходимо учитывать как факторы развития современных АПС, имеющие прямое отношение к глобальным целям ФАО, так и тенденции, способствующие запуску преобразований в национальных агропродовольственных системах.

Таблица 1. Факторы и соответствующие им тенденции, определяющие развитие современных агропродовольственных систем

\begin{tabular}{|c|c|c|}
\hline & Факторы & Тенденции \\
\hline 1 & Динамика народонаселения и урбанизация & $\begin{array}{l}\text { Увеличение и изменение спроса на продоволь- } \\
\text { ствие }\end{array}$ \\
\hline 2 & Взаимная зависимость стран & $\begin{array}{l}\text { Формирование агропродовольственных систем } \\
\text { мира }\end{array}$ \\
\hline 3 & Геополитическая нестабильность & $\begin{array}{l}\text { Разрастание конфликтов, включая конфликты } \\
\text { вокруг ресурсов }\end{array}$ \\
\hline 4 & $\begin{array}{l}\text { Факторы неопределенности, неожиданно возника- } \\
\text { ющие события }\end{array}$ & $\begin{array}{l}\text { Вероятностное развитие агропродовольственных } \\
\text { систем }\end{array}$ \\
\hline 5 & $\begin{array}{l}\text { Цены на продовольствие, которые в реальном вы- } \\
\text { ражении ниже цен 70-х годов, но выше, чем в 80-е } \\
\text { и 90-е годы XX века }\end{array}$ & $\begin{array}{l}\text { Отсутствие адекватной ценовой политики (цены } \\
\text { не отражают в полной мере социальные и экологи- } \\
\text { ческие издержки, связанные с продовольствием) }\end{array}$ \\
\hline 6 & $\begin{array}{l}\text { Инновации и достижения науки, включая иннова- } \\
\text { ционные технологии и системные подходы }\end{array}$ & $\begin{array}{l}\text { Внедрение цифровых технологий, развитие био- } \\
\text { технологии, агроэкологии, сберегающих техноло- } \\
\text { гий, органического сельского хозяйства }\end{array}$ \\
\hline 7 & $\begin{array}{l}\text { Государственные инвестиции } \\
\text { в агропродовольственные системы }\end{array}$ & Зачастую инвестиции недостаточны \\
\hline 8 & $\begin{array}{l}\text { Капиталоемкость/информационная насыщен- } \\
\text { ность производства }\end{array}$ & $\begin{array}{l}\text { Рост капиталоемкости производства, в том числе } \\
\text { продовольствия и продукции сельского хозяйства }\end{array}$ \\
\hline 9 & Структура потребления и питания & $\begin{array}{l}\text { Изменение модели поведения потребителей в } \\
\text { пользу более здорового питания }\end{array}$ \\
\hline 10 & $\begin{array}{l}\text { Дефицит и ухудшение состояния природных } \\
\text { ресурсов }\end{array}$ & $\begin{array}{l}\text { Увеличение количества истощенных земельных, } \\
\text { водных и почвенных ресурсов, ухудшение биораз- } \\
\text { нообразия }\end{array}$ \\
\hline 11 & Эпидемии и ухудшение состояния экосистем & $\begin{array}{l}\text { Нарастание воздействия трансграничных вредите- } \\
\text { лей и болезней растений, наступление сельскохо- } \\
\text { зяйственных угодий на некультивируемые земли } \\
\text { и леса }\end{array}$ \\
\hline 12 & Изменение климата & $\begin{array}{l}\text { Рост экстремальных погодных явлений, негативно } \\
\text { влияющих наагропродовольственные системы и } \\
\text { природные ресурсы }\end{array}$ \\
\hline
\end{tabular}

Составлено по: [14] 
На наш взгляд, с проблемами достижения устойчивого развития АПС прямо или косвенно коррелируют задачи следующих целей: ЦУР 1,2 , $3,5,6,7,8,9,11,13,14,15$." Здесь следует отметить, что согласно данным, представленным до начала пандемии COVID-19, «прогресс в сфере производства продовольствия и ведения сельского хозяйства с позиций устойчивости остается недостаточным и мир не успевает достичь соответствующих целей к 2030 году» [15]. Эти выводы находят подтверждение и в представленном Российской Федерацией на Политическом форуме ООН в 2020 году отчетном документе - Добровольном национальном обзоре, в котором отмечается, что «прогресс страны в экономической, социальной и экологической сферах пока является крайне медленным и нестабильным» [13].

Помимо вышесказанного, необходимость развития теоретических положений и методологического аппарата функционирования организационно-экономического механизма достижения ЦУР в национальной АПС продиктована неоднозначностью трактовки данной категории. Так, Удальцова Н.Л. определяет, что «организационно-экономический механизм функционирования отрасли представляет собой важную составную часть всего хозяйственного механизма и может быть определен как совокупность организационно-экономических структур, формирующих отрасль национальной экономики, и уровней управления, включающих законодательные, финансово-экономические и организационно-административные методы воздействия...» [11]. В свою очередь, исследователи Паршуков Д. В., Ходос Д.В. и Иванов С.Г. рассматривают подобный механизм как «совокупность экономических (ценообразование, налогообложение, страхование, финансирование и т.д.) и административно-правовых (нормативноправовые ограничения, пучок правомочий прав собственности, аграрная политика государства и т.д.) рычагов воздействия и форм организации социально-производственных процессов, обеспечивающих функционирование и устойчивое развитие сельскохозяйственных отраслей и сельских территорий» [7].

Следует заметить, что зачастую отечественные авторы ограничиваются проблемами совершенствования организационно-экономического механизма агропромышленного комплекса лишь в его отдельных отраслях [1,9]. Между тем публикации, посвященные проблеме формирования организационно-экономического механизма в АПС с учетом концепции ЦУР ООН, в отечественной научной литературе пока что отсутствуют.

Учитывая представленные мнения российских ученых, предлагаем рассматривать организационно-экономический механизм достижения ЦУР в национальной агропродовольственной системе как совокупность институциональных, организационных, экономических, кадровых, производственных и инновационных составляющих с целью мотивации производственной, экологической, социальной, инвестиционной, инновационной деятельности, обеспечивающих продовольственную независимость страны, равновесное, сбалансированное состояние экономической, социальной и экологической составляющих национальной агропродовольственной системы.

Разработанная нами концептуальная версия организационно-экономического механизма достижения ЦУР в национальной агропродовольственной системе представлена на рис. 1.

Обсуждение. Как видно на рисунке 1, ключевые ЦУР ООН составляют сердцевину общей методики трансформации национальной агропродовольственной системы в аспекте достижения ее устойчивости с помощью различных методов и инструментов, выбор которых будет зависеть от конкретной проблематики и соответствующих им целей и задач устойчивого развития АПС. Полагаем, что целевыми ориентирами (результатами) реализации подобного организационно-экономического механизма станут совершенствование производства, повышение качества питания и состояния окружающей среды, а также содействие повышению качества жизни.

\footnotetext{
* Ц ЦУР 1 - Ликвидация нищеты, ЦУР 2 - Ликвидация голода и устойчивое сельское хозяйство; ЦУР 3 - Хорошее здоровье и благополучие; ЦУР 5 - Гендерное равенство); ЦУР 6 - Чистая вода и санитария; ЦУР 7 - Доступная чистая энергия; ЦУР 8 - Достойная работа и экономический рост; ЦУР 9 - Инновации и инфраструктура; ЦУР 10 - Уменьшение неравенства; ЦУР 11 - Устойчивые города и населенные пункты; ЦУР 12 - Ответственное потребление и производство; ЦУР 13 - Борьба с изменениями климата; ЦУР 14 - Сохранение морских экосистем и ЦУР 15 - Сохранение экосистем суши.

См источник: Преобразование нашего мира: Повестка дня в области устойчивого развития на период до 2030 года. ООН, Нью-Йорк. 2015. URL: http://docs.cntd.ru/document/420355765
} 


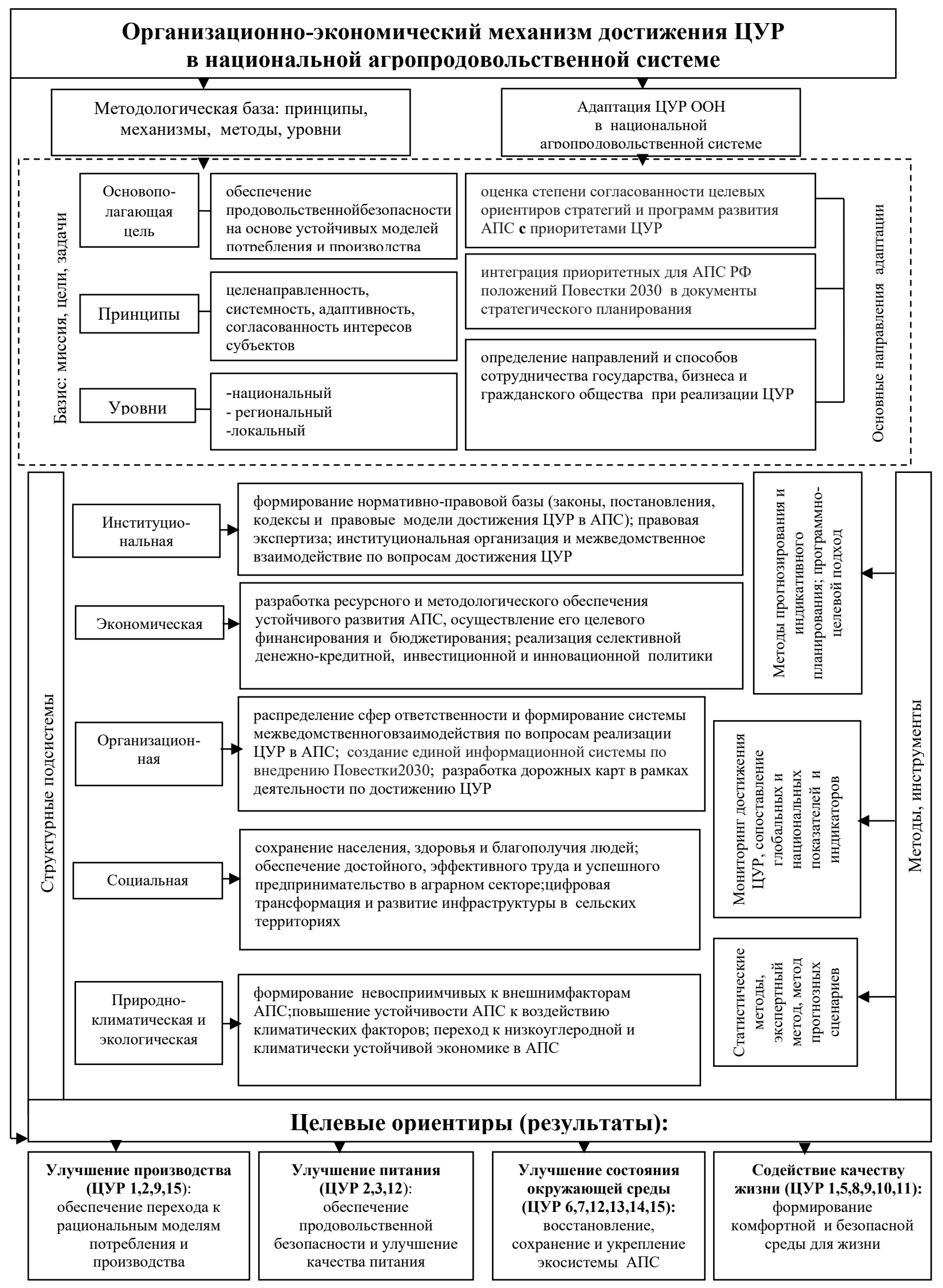

Рисунок 1.Организационно-экономический механизм достижения ЦУР в национальной агропродовольственной системе: концептуальная версия 
В свою очередь, значительная часть деятельности, направленной на улучшение производства, призвана содействовать достижению ЦУР 1 , $2,14,15$; в рамках улучшения качества питания особое значение имеют ЦУР 2, 3, 12; улучшение состояния окружающей среды сопряжено с достижением ЦУР 6, 7, 12, 13, 14, 15; улучшение качества жизни - с достижением сбалансированного и разнообразного комплекса ЦУР $1,5,8$, 9, 10,11 , в том числе направленных на обеспечение инклюзивности и реализацию принципа «никто не должен остаться без внимания» [18].

Отсутствие методологии реализации концептуальных положений по переходу к более устойчивым агропродовольственным системам, способствующим улучшению производства, качества питания, состояния окружающей среды и качества жизни, явилось основанием для выделения структурных подсистем предлагаемого нами организационно-экономического механизма достижения ЦУР в АПС. В частности, к ним мы относим институциональную, экономическую, социальную, природно-климатическую и экологическую подсистемы.

Так, актуализируя институциональную подсистему подобного механизма, отметим, что, несмотря на отсутствие утвержденных Целей устойчивого развития на период до 2030 года, в 2018 году в России все же были сформулированы Национальные цели развития и зафиксированы в Указе Президента РФ «О национальных целях и стратегических задачах развития Российской Федерации на период до 2024 года» (от 7 мая 2018 года № 204).В 2020 году подписан указ № 474 «О национальных целях развития Российской Федерации на период до 2030 года», который скорректировал долгосрочные целевые ориентиры, определенные Указом Президента от 7 мая 2018 года № 204. В настоящее время с учетом национальных целей развития РФ, а также инструментов и механизмов их достижения на среднесрочный период формируются концептуальные подходы к разработке Стратегии социально-экономического развития Российской Федерации на период до 2050 года (Стратегия 2050), утверждение которой предполагается к концу текущего года.Однако нельзя не согласиться с мнением, что «система управления достижением ЦУР к настоящему моменту не централизована, мероприятия не связаны между собой в единый план, а их реализация но- сит разрозненный характер» [8].

Учитывая вышеизложенное, в рамках формирования и последующей реализации организационно-экономического механизма достижения ЦУР ООН в агропродовольственной системе в его институциональной подсистеме необходимо предусмотреть следующие направления: 1. разработку и утверждение долгосрочных комплексных национальных целей устойчивого развития; 2. интеграцию приоритетных для РФ положений Повестки 2030 в документы стратегического планирования; 3. распределение сферы ответственности федеральных органов исполнительной властии организация взаимодействия министерств и ведомств по вопросам реализации Повестки 2030; 4. разработку механизмов стимулирования ответственного (с учетом ЦУР) ведения бизнеса; 5. создание единой информационной системы по внедрению Повестки 2030.

С другой стороны, в рамках экономической подсистемы подобного механизма необходимо разрабатывать ресурсное и методологическое обеспечение устойчивого развития АПС; осуществлять его целевое финансирование и бюджетирование; проводить селективную денежно-кредитную, инвестиционную политику и развивать инновации.

Социальная подсистема имеет исключительно важное значение в аспекте устойчивости АПС, так как связана с защитой прави улучшением условий жизни в сельских районах, социальным благополучием, сохранением населения и развитием человеческого капитала [6, 22], обеспечением достойного, эффективного труда, успешного предпринимательства в аграрном секторе и развитием инфраструктуры в сельских территориях. Кроме того, необходимо осуществлять инвестиции в аграрную науку и образование, реализуя творческий и инновационный потенциал российской системы высшего образования [21].

И, наконец, решение проблем, связанных с природно-климатической и экологической подсистемами (изменение климата, повышение интенсивности стихийных бедствий, общее тотальное ухудшение состояния экосистем) требует применения комплекса экономических, правовых, организационных и других мер по повышению устойчивости агропродовольственных систем. 


\section{Выводы.}

Таким образом, общемировые тенденции устойчивого развития национальных агропродовольственных систем, которые в значительной степени актуальны и для России, говорят о нарастании значимости разработки организационно-экономического механизма достижения ЦУР ООН в национальной АПС.

По мнению авторов статьи, в российской агропродовольственной системе в настоящее время стоит задача ускорения процессов достижения целей устойчивого развития на основе формирования структурных подсистем подобного механизма - институциональной, организационной, экономической, социальной, природно-климатической и экологической. Для обеспечения продовольственной безопасности и создания устойчивых агропродовольственных систем необходимо дальнейшее преобразование АПС национального, регионального и локального уровней с учетом концепции целей устой- чивого развития на основе реализации предложенного организационно-экономического механизма.

В целом разработка подходов и методов по формированию и реализации организационноэкономического механизма достижения ЦУР ООН в АПС России позволит внести весомый вклад в развитие теории устойчивости агропродовольственных систем.

Представленные в статье оценки, обобщения и выводы получены с использованием качественных исследовательских подходов и могут потребовать в дальнейшем более детального анализа и количественных оценок.

Исследование выполнено при финансовой поддержке РФФИ в рамках научного проекта № 20-010-00375 «Методология формирования и разработка организационно-экономического механизма достижения цзелей устойчивого развития в национальной агропродовольственной системе».

\section{Библиографический список}

1. Алтухов А.И. Совершенствование организационно-экономического механизма развития российского зернового экспорта // Экономика сельского хозяйства России. 2020. №9. С. 94-100.

2. Бобылев С. Н., Григорьев Л. М. В поисках новых рамок для целей устойчивого развития после COVID-19: cтраны БРИКС // Научные исследования экономического факультета. Электронный журнал. 2021. Т. 13. № 1 (39). C. 25-51.

3. Викторова Е. В., Петренко Д. А. Реализация целей устойчивого развития: Европейский и российский опыт: сборник научных статей по материалам конференции / под ред. канд. экон. наук Е.В.Викторовой. СПб.: Изд-во СПбГЭУ, 2019. С.17-29.

4. Довготько Н.А., Андрющенко С. А., Чередниченко О.А., Скиперская Е.В. Опыт Европейского союза по реализации целей устойчивого развития в сельском хозяйстве и возможности его применения в России // Международный сельскохозяйственный журнал. 2021. № 1 (379). С. 74-80.

5. Инновационное развитие агропромышленного комплекса в России. Agriculture 4.0 [Текст]: докл. к XXI Апр. междунар. науч. конф. по проблемам развития экономики и общества, Москва, 2020 г. / Н. В. Орлова, Е. В. Серова, Д.В.Николаев и др.; под ред. Н. В. Орловой; Нац. исслед. ун-т «Высшая школа экономики». М.: Изд. дом Высшей школы экономики, 2020. 128 с.

6. Касаева Т.В. Расширительная трактовка структуры человеческого капитала. Terra Economicus. 2013. T. 11. № 2-2. С. 21-27.

7. Паршуков Д. В., Ходос Д. В., Иванов С. Г. Организационно-экономический механизм развития аграрного сектора // Эпоха науки. 2015. № 4. С.25.

8. Прокопов Ф.Т., Киселев А.Н. Управление рисками устойчивого развития // Бизнес. Общество. Власть. 2020. № 2-3 (36-37). С.41-72.

9. РубаеваО.Д., КачуринаЕ.П. Диагностика развития организационно-экономического механизма развития малого и среднего бизнеса в молочной отрасли скотоводства // В сборнике: Актуальные вопросы социально-экономических, технических и естественных наук. Материалы Национальной (Всероссийской) научной конференции Института агроинженерии. Челябинск, 2021. С. 69-75.

10. Сахаров А. Г., Колмар О. И. Перспективы реализации Целей устойчивого развития ООН в России // Вестник международных организаций. Т. 14. 2019. № 1. С. 189-206.

11. Удальцова Н.Л. Организационно-экономический механизм функционирования отрасли национальной экономики // Экономические науки. 2012. № 6(91). С.94-98. 
12. Чередниченко О.А., Довготько Н.А., ЯщаловаН.Н. Устойчивое развитие агропродовольственного сектора: российские приоритеты и направления адаптации Повестки дня-2030 // Экономические и социальные перемены: факты, тенденции, прогноз. 2018. Т. 11. № 6. С. 89-108.

13. Добровольный национальный обзор хода осуществления Повестки дня в области устойчивого развития на период до 2030 года.URL: https://sustainabledevelopment.un.org/content/documents/26421VNR_2020_Russia_ Report_Russian.pdf (дата обращения 15.08.2021)

14. К 2030 году численность населения мира увеличится на миллиард человек. URL: https:/www.news.un.org)ru/ story/2017/06/130681 (дата обращения 15.08.2021)

15. Мониторинг достижения связанных с продовольствием и сельским хозяйством показателей ЦУР, 2020 год. URL: https://www.labourcentralasia.org/upload/iblock/56a/56aa01d4eec37bea1f7758d2f688ef9c.pdf.(дата обращения 15.08.2021)

16. Преобразование нашего мира: Повестка дня в области устойчивого развития на период до 2030 года. ООН, Нью-Йорк. 2015. URL: http://docs.cntd.ru/document/420355765 (дата обращения: 12.06.2021)

17. Региональная конференция ФАО для Европы. 31-я сессия Региональной конференции ФАО для Европы. URL: https://www.fao.org>about/meetings/erc31/ru/ (дата обращения 05.08.2021)

18. Среднесрочный план на 2022-2025 годы и Программа работы и бюджет на 2022-2023 годы. Продовольственная и сельскохозяйственная организация Объединенных Наций Рим, 2021 год. URL: https://www. www. fao.org/pwb (дата обращения 12.08. 2021)

19. Стратегическая рамочная программа на 2022-2031 годы. URL: https://www.fao.org. (дата обращения 20.08. 2021)

20. ФАО, МФСР, ЮНИСЕФ, ВПП и ВОЗ. 2020 год. Краткий обзор. Положение дел в области продовольственной безопасности и питания в мире - 2020. Преобразование продовольственных систем для обеспечения финансовой доступности здорового питания. Рим, ФАО. URL: https:/www. https://doi.org/10.4060/ca9699ru (дата обращения 17.08. 2021)

21. Gorbunov A.P., Gorbunova N.N., EfimovaE.V., Kilinkarova S.G. The model of the formation and implementation of the creative and innovative potential of the Russian system of higher education // International Journal of Economics and Financial Issues. 2016. T. 6. № 1. C. 139-146.

22. Politkina K.I., Anufrienko S.V., Elkin V.V., Dneprov M.Yu. Innovative ecological and economic aspects of the conceptual transformation of alienation in the genesis of the civilization // AmazoniaInvestiga. 2019. T. 8. № 20.C. 640-647.

23. Jianguo Liu, Vanessa Hull, H.Charles J. Godfray, David Tilman, Peter Gleick, Holger Hoff, Claudia Pahl-Wostl, Zhenci Xu, Min Gon Chung, Jing Sun, Shuxin Li. Nexus approaches to global sustainable development. Nat. Sustain. 2018, 1, 466-476. (дата обращения 17.08. 2021)

24. Vardanega R., Prado J.M., Meireles M.A. Adding value to agri-food residues by means of supercritical technology. J. Supercrit. Fluids 2015, 96, 217-227 (дата обращения 23.08. 2021)

25. Sachs J., Schmidt-Traub G., Kroll C., Lafortune G., Fuller G., Woelm F. The Sustainable Development Goals and COVID-19.Sustainable Development Report 2020. Cambridge: Cambridge University Press. URL: https://www. sdgindex.org`reports/sustainable-development...2020/ (дата обращения 06.08. 2021)

26. Landmark analysis by Elsevier maps research data as UN Sustainable Development Goals reach fifth anniversary. URL: https://www.https://www.prnewswire.com/news-releases/landmark-analysis-by-elsevier-maps-researchdata-as-un-sustainable-development-goals-reach-fifth-anniversary-301136167.html ～(дата обращения 13.08.2021) 